\title{
A identificação no autismo: Um estudo do vínculo com animais nas autobiografias
}

Marina Bialer

\section{RESUMO}

O presente artigo focaliza a edificação de identificações imaginárias compensatórias ancoradas no vínculo de autistas com animais. A análise qualitativa dos livros autobiográficos evidencia como autistas que manifestaram um quadro sintomatológico severo na infância saíram do quadro de autismo clássico, puderam se tornar falantes e se desenvolver em todas as áreas a partir do vínculo com um animal. Abordamos nas autobiografias acerca dos autistas Iris, Dale, Fraser e George, o vínculo paradigmático com Thula, Henry, Billy e Ben, ancorando esse percurso da edificação das identificações constitutivas do eu. Após a descrição e caracterização dos traços e funções incorporadas nessas relações identificatórias, abordaremos algumas consequências destas. Apesar de não serem traços incorporados dos outros parentais, destacamos a viabilidade de uma nova regulação libidinal no autismo. Articulando autores no interior da psicanálise que se dedicaram a pensar o autismo com os relatos autobiográficos, consideramos que essa abordagem permitiu cumprir o objetivo proposto de aprofundar o conhecimento científico acerca do autismo.

Palavras-chave: autismo; autobiografia; psicanálise; animal; identificação.

\section{ABSTRACT}

\section{Identification in autism: A study of the attachment with animals in autobio-} graphies

This paper focuses on the construction of compensatory imaginary identifications anchored on the attachament of autists with animals. Our qualitative analysis of these autobiographical books evidenced how autistic children who manifested severe symptoms in childhood, left the classic autism, became speaking autistic and were able to develop in all areas, anchored on the relation with an animal. Through the autobiographies about autists Iris, Dale, Fraser and George, we analyse the paradigmatic attachment with Thula, Henry, Billy and Ben, anchoring this path of construction of the constitutive identifications of the ego. After the description and characterization of the traits and functions incorporated in this identificatory relationships we'll cover some consequences of those. Despite not being traits incorporated from others/parents, we highlight the feasibility of a new libidinal regulation in autism. Articulating authors in the field of psychoanalysis that dedicated themselves to think about autism with the autobiographical accounts, we consider this approach enabled us to fulfill the proposed goal of deepening scientific knowledge about autism.

Keywords: autism; autobiography; psychoanalysis; animal; identification.

Na metapsicologia freudiana, as identificações são momentos paradigmáticos da constituição do aparelho psíquico. Há o efeito momento mutativo da constituição da Gestalt imaginária, ancorando-se na "gênese do ego via identificação narcísica" (Campos, 2009, p. 51) e de seus importantes efeitos de organização psíquica a partir do surgimento da identificação do 'eu' oriundo do espelhamento. Nessa perspectiva, a identificação é um retrato da impressão do outro no aparelho psíquico e da importância do outro para a constituição do psiquismo humano. Essa "introdução do outro enquanto modelo e possibilidade do 'eu', ou seja, enquanto

\section{Sobre a Autora}

M. B.

orcid.org/0000-0003-4650-5138 Universidade de São Paulo (USP)- São Paulo, SP mbialer@hotmail.com

\section{Direitos Autorais}

Este é um artigo de acesso aberto e pode ser reproduzido livremente, distribuído, transmitido ou modificado, por qualquer pessoa desde que usado sem fins comerciais. trabalho é disponibilizado sob a licença Creative Commons CCBY-NC.

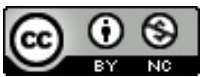


fator constituinte e não apenas constituído" (Campos, 2009, p. 17) destaca o papel dessa alteridade que constitui o 'eu' e que altera a dinâmica da libido, retratando "um processo no qual um objeto do mundo exterior não é apenas representado na forma de imagem, mas também passa a organizar o próprio espaço mental, como suporte para a gênese de uma instância psíquica" (Campos, 2009, p. 18). Nesse modelo de constituição do aparelho psíquico, "a alteridade está incrustada na gênese do aparelho psíquico" (Campos, 2009, p. 18) desembocando em um "modelo da introjeção de aspectos do objeto no aparelho psíquico" (p. 55), de modo que pode-se dizer que a identificação "diz respeito ao processo psicológico pelo qual o indivíduo assimila um aspecto, propriedade ou atributo do outro, se transformando segundo o modelo desse outro" (Campos, 2009, p. 55) e, "nesse sentido, a identificação diz respeito ao processo que permite a transformação da estrutura do ego em sua relação com o outro" (Campos, 2009, p. 55).

A psicanalista Kupfer (2004) sugere pensarmos que o autista mantém um esquema corporal independente da construção da imagem do corpo próprio, cuja constituição está imbricada à constituição egóica e ao espelhamento viabilizado pela alienação imaginária a um outro humano, o que remete ao autismo enquanto "uma doença da libido" (Soler, 1999, p. 228). Nesse âmbito, como o autista pode se apropriar do fluxo de energia vital se está desconectado do campo da libido e se não há um enodamento de uma imagem narcísica? No presente texto abarcamos a hipótese de que por meio das identificações imaginárias com seus duplos (animais), os autistas analisados estão edificando uma construção identitária alicerçada na inscrição dos traços destes outros, que Ihes viabiliza uma forma de se apropriar da libido, a partir da inscrição dessa marca do outro no campo do imaginário e da identificação imaginária com este outro não humano.

No autismo, o psicanalista Maleval (2009) tem sustentado a hipótese da viabilidade de uma identificação compensatória, correlata à construção da imagem de si, baseada na ideia que a função de espelhamento pode ser operacionalizada por meio de invenções que viabilizam a inscrição da imagem de um outro, como um modelo de identificação imaginária, que alicerça o surgimento de uma Gestalt, que forma e molda a relação com o próprio corpo e com os outros, favorecendo um modo de sair do isolamento autístico e se relacionar com as pessoas. Com esse intuito, no presente artigo, iremos analisar nas autobiografias familiares acerca dos autistas Iris (Carter-Johnson, 2016), Dale (Gardner, 2008, 2013), Fraser (Booth, 2014) e George (Romp, 2010) e o vínculo paradigmático com um animal, ancorando um percurso de edificação das identificações imaginárias constitutivas do eu.

\section{MÉTODO}

Trata-se de um artigo baseado na análise qualitativa dos escritos de quatro pais de autistas, tendo como instrumental de leitura a psicanálise, utilizada para a análise desses textos autobiográficos, buscando contemplar a maneira singular de construção de saber no campo psicanalítico. Conforme sublinhado por Campos e Coelho Jr. (2010), a metodologia de leitura que orienta nossa pesquisa não se pauta, pois, na aplicação de explicações já prontas às quais deve se moldar o material analisado. Justamente o contrário, potencializar o método de interpretação de textos seguindo o modelo psicanalítico de pesquisa, de modo a viabilizar que possa surgir, de fato, o inesperado e o original da clínica psicanalítica. Consideramos que o método de leitura psicanalítico permitiu a derivação de um instrumental de leitura do material autobiográfico, propiciando o surgimento de novas concepções acerca da identificação no autismo e do conhecimento psicanalítico sobre essa temática.

\section{RESULTADOS}

O livro da britânica Arabella (Carter-Johnson, 2016) destaca a importância do vínculo de sua filha autista, Iris, com uma gata. Arabella acreditava no valor terapêutico do enlace com os animais, mas suas primeiras tentativas de ajudar a fiIha por esta via fracassaram. Primeiro, haviam tentado uma cachorra Golden Retriever, Willow, que ficava lambendo e demandando atenção, e Iris ficou totalmente em pânico, parou de dormir e evitava entrar em qualquer ambiente onde estivesse Willow. Depois, tentaram realizar uma equoterapia, mas ela não demostrava qualquer interesse pelos cavalos. Arabella resolve que estas foram tentativas prematuras e decide apostar em um gato. 0 vínculo ${ }^{1}$ de Thula e Iris foi imediato; ela era uma gata ativa e extremamente afetiva, e parecia interessada em tudo o que Iris fazia. Enquanto Iris desenhava, Thula ficava ao seu lado, olhando atentamente enquanto mexia os pincéis, sendo que eventualmente pegava um pincel que brincava de jogar de um lado para o outro.

Thula adorava imitar os movimentos de Iris. Observava seus movimentos e tentava repeti-los, brincando em um vínculo que se tornava cada dia mais forte e "encantador" (Carter-Johnson, 2016, p. 224). E quanto mais se torna intensa esta relação, mais Iris se mostra afetiva com ambos os pais, abraçando-os com cada vez mais intensidade e frequência. Também começa a falar na frente dos avós maternos e pegálos pela mão durante as atividades.

Arabella decide aproveitar a tranquilidade de Iris na presença da gata e coloca um colete/tipo coleira em Thula e ela se torna a companheira de Iris em quase todas as atividades 


\section{-3: INTERACÃO EM LF PSICOLOGIA}

externas: passeios de barco, viagens no carro e passeios de bicicleta. Depois de um passeio de bicicleta, quando usualmente Iris saía correndo para remover sua blusa, sempre demonstrando intensa irritação com estas roupas, ela nem parece mais se incomodar e fica horas com a blusa. A hipótese da mãe é a de que por se sentir segura na relação com Thula, ela pode se tornar mais flexível e viver a vida mais livremente.

Iris fica tão mais aberta a novas experiências e recupera a tranquilidade tão mais rápido na presença de Thula que Arabella resolve tentar recorrer à ajuda felina em situações em que a filha geralmente manifestava crises e nas quais, na companhia da gata, Iris se distrai e para de chorar.

A abertura ao outro viabilizado pelo vínculo com um felino é ainda mais extensiva no exemplo de George. A autobiografia de Julia Romp (2010) enfoca a função psíquica exercida por Ben, um gato vira-lata, que foi a ponte indispensável para a saída de seu filho George de um quadro de isolamento e retraimento autísticos. Aos dois anos de idade, ele permanecia insone, ficava cantando ou repetindo "Buzz Lightyear" (Romp, 2010 , p. 19) sem parar e seus berros eram prementes. Quando as coisas não saíam como previsto ou como queria, George mordia os braços até sangrar ou puxava fortemente o próprio cabelo até arrancá-lo. Ele parecia "atormentado pela vida" (Romp, 2010, p. 22): quando acordado, ela nunca podia tocá-lo e tentava se espreitar à noite no seu quarto para olhálo e eventualmente encostar muito levemente no seu corpo. Até os dez anos de idade, George continuava avesso a qualquer demonstração de afeto, não brincava com as outras crianças, dormia entre três e quatro horas por noite, tinha crises de raiva, dificuldade com comunicações sociais, intensas perturbações sensórias, necessidade de uma rotina imutável e obsessões que só aumentavam.

No entanto, um dia "um gato de rua que ... parecia como se tivesse lutado dez rounds contra o Mike Tyson" (Romp, 2010, p. 65), tornou-se "a chave para destravar todo o amor e toda imaginação que haviam repousado trancados dentro de George por tanto tempo" (Romp, 2010, p. 65). Ben, como a grande maioria dos felinos domésticos, tinha um gosto pela mesmice e pela rotina, adorando acompanhar George em suas repetições e rituais, o que o tornou particularmente suscetível a ser apropriado enquanto um companheiro confiável, previsível; Ben era calmo como "um velho sábio com olhos serenos" (Romp, 2010, p. 95) com quem era viável compartiIhar atividades outrora realizadas de modo isolado.

Ao contrário da usual aversão ao toque, George não rejeitou o contato corporal com seu gato e ambos deitavam juntos assistindo a um filme. Já nos primeiros meses de convivência, George começa a inventar histórias sobre Ben que são compartilhadas com Julia. E enquanto contava estas histórias ou interagia com Ben, pela primeira vez na vida, George gargalhava em um prazer compartilhado.

Ben acompanhava George por toda a casa, sempre na mesma rotina. No dia a dia, quando George estava em casa, Ben era sua "cola" (Romp, 2010, p. 88). Eles faziam tudo juntos; quando George toma banho, Ben fica ao seu lado, observando-o até que George faça bolinhas de sabão para que ele corra atrás delas. George "dialogava" com Ben, personificando a voz do amigo gato.

Apropriando-se de uma voz similar àquela dos desenhos animados, George contava histórias imaginárias - Ben havia sido um piloto de aviões, era um paraquedista que pulava dos telhados das casas, havia realizado uma dieta com Slim Shake, mas estava trapaceando comendo chocolate, etc... Progressivamente, George personificou a voz de gato para contar para a mãe tudo o que aprendia na escola. George precisava do intermédio da voz felina por meio do qual conseguia expressar algo pessoal, mas nessas condições sua abertura ao outro era muito mais abrangente e intensa. No transcorrer do tempo, toda a família e amigos adotaram essa "cat talk" (Romp, 2010, p. 104) para conversar entre si quando estavam com George. Ao contrário do isolamento e retraimento que havia prevalecido até então, por meio do intermédio da voz de gato, ele podia conversar sobre os mais variados assuntos.

O intermédio de Ben é utilizado por Julia para educar George, por exemplo, a parar de arrotar. Após anos sem sucesso, quando George arrota na mesa, ela começa a lhe dizer que o gato não gosta daquilo. Ao invés de uma crise nervosa como acontecia usualmente nessas situações, George pergunta por que Ben não gosta de arrotos, ao que ela responde personificando o gato para dizer que Ben acha que isto é rude e ele é um gato educado. Quando George demonstra surpresa, Julia insiste que Ben não concorda com arrotos por uma questão de educação. Depois dessa conversa, sempre que arrotava, colocava um papel na frente e tentava ser o mais discreto e educado possível.

Julia realça que o tom utilizado se aproximava de um manhês. Ele não utilizava o tom da própria voz, mas o que Maleval (2015) designa como uma voz por substituição. Por meio do intermédio da voz felina, surgia um espaço de prazer nas interações com o filho e ele podia se comunicar de uma maneira que outrora era impossível. A única condição era que todas as pessoas adotassem o tom da língua felina marcada pela prosódia do manhês.

Pelo intermédio do gato, seu interesse pelos conhecimentos se amplia e, pela primeira vez na vida, ele pode realizar várias questões e responder a questões acerca de inúmeros temas cotidianos. Não somente é despertada uma maior avidez intelectual, como George também se mostra mais dispo- 


\section{- M. INTERACÃO EM LF PSICOLOGIA}

nível afetivamente, podendo estabelecer interações ternas com sua mãe. Havia uma inibição quando deveria expressar qualquer temática mais marcada de emoção; George não conseguia falar diretamente que amava outra pessoa, mas podia falar para sua mãe, por intermédio de Ben: "Você sabe que o Ben te ama, não sabe, mamãe?" (Romp, 2010, p. 161), ou quando Julia falava ao telefone com a avó, quando estivesse fora do campo da visão, ele berrava que a amava.

A relação com Ben viabilizou a aquisição de uma dinamização do seu funcionamento psíquico, de uma abertura para o mundo e para o outro, sendo que uma vez quando Ben desaparece alguns meses, George se isola novamente, suas estereotipias retomam, seus progressos param e regridem. Ele fica desvitalizado, desinteressado por tudo e todos, até o retorno de seu duplo/gato, quando obtém uma revitalização libidinal e abertura de interesse pelo mundo e pelos outros.

Durante muitos anos George demonstrara uma severa aversão a ser tocado por outro humano, mas um dia, por intermédio de Ben, há um momento paradigmático. Como outras vezes, George começa a se mover como se fosse um gato e aos poucos se esfrega nas pernas de Julia, senta-se no sofá e se deita sobre ela, da maneira como Ben se deitava sobre seu corpo, lentamente encostando sua cabeça sobre a mãe. Seu corpo fica completamente relaxado e ele começa a contar as histórias de Ben enquanto um lutador de sumô que é faixa preta em karatê. Julia acaricia o seu cabelo da mesma maneira como o vira agradando Ben, enquanto ele conta uma história de Ben viajando.

Já a autobiografia da britânica Louise (Booth, 2014) enfoca a mudança psíquica viabilizada pelo vínculo de seu filho autista, Fraser, com um gato vira-lata, Billy. Já no primeiro encontro, Billy se colocou delicadamente sobre o gato e, em alguns instantes, eles estavam juntos "como se não houvesse ninguém mais no mundo além deles" (Booth, 2014, p. 15). Perguntado se queria que Billy fosse para casa com eles, responde imediatamente que sim. Quando o gato entra na sua casa, quase imediatamente Billy e Fraser já estão interagindo, deitados lado a lado no carpete. Geralmente, Fraser evitava intimidade corporal com estranhos, mas com Billy, em questão de minutos um já fazia carinho na face do outro.

No dia a dia, o vínculo com Billy expandia cada vez mais a relação de Fraser com o mundo. Ele nunca havia tolerado ficar no jardim, mas toda hora que precisa procurar o gato, que adora escalar as árvores da vizinhança, tem que sair da casa e ir até o jardim para procurá-lo. Durante anos, Fraser tinha estabelecido uma relação especial com um laço de cadarço que mexia de modo estereotipado, principalmente quando nervoso. Quando realizava esses movimentos, parecia alheio ao mundo, perdurando sua fixação exclusiva com esse objeto em detrimento dos outros. No entanto, após o vínculo com
Billy, espontaneamente Fraser não recorre mais ao cadarço. A segurança que ele sentia com Billy havia lhe permitido não precisar mais desse objeto de fixação. Suas crises de nervosismo se tornavam menos intensas e nas que ainda ocorriam, seu gato ia em sua direção, ficava olhando-o calmamente, ajudando-o a retomar a tranquilidade, de modo que a presença de Billy se transformou em um porto seguro que the possibilitava tolerar mudanças sem que fossem desencadeadas crises.

Aos três anos de idade, esta mudança paradigmática de Fraser viabilizada pela aquisição de um sentimento de segurança, que the permitiu se abrir para o mundo e para os outros, também foi marcante na vida escolar. Louise descreve com pertinência que antes da chegada de Billy, havia o "mundo-Fraser" (Booth, 2014, p. 84), mas depois deste vínculo surgiu um mundo compartilhado, alicerçado no sentimento de segurança e tranquilidade que Billy oferecia.

Fraser estava sempre sussurrando algo baixinho para Billy, como se tivessem desenvolvido uma "linguagem secreta" (Booth, 2014, p. 77) compartilhada, mas além disso, Billy era seu tema predileto e a ponte temática para ele falar com os outros. A intimidade entre eles era crescente e Billy parecia se sentir mais calmo e encorajado para se relacionar com os outros e aceitar mudanças na sua rotina, o que permitia que ele interagisse com várias outras pessoas.

Aos cinco anos de idade, ele entra na escola regular e tem não somente um ótimo desempenho acadêmico, como pode se desenvolver bem social e emocionalmente, estabelecendo suas primeiras amizades com colegas. A relação com Billy, enquanto alicerce identificatório, ancorou a construção de inúmeras capacidades psíquicas de Fraser: cada vez mais ele se colocou no lugar do gato, imaginando como o gato estava se sentindo e o que ele estava pensando e utilizou todo esse material para construir um importante repertório biográfico. Essa relação tornou-se um paradigma que alterou todas as suas outras relações, desdobrando-se na possibilidade de se interessar pelo mundo e pelas outras pessoas de modo cada vez mais intenso e extensivamente.

Nuala (Gardner, 2008, 2013) relata a importância de um cachorro, Henry, para a saída do quadro de retraimento autístico do primogênito, Dale. No decorrer da primeira infância, Dale começou a manifestar medos intensos e crises de nervosismo, e somente se tranquilizava ao ouvir a repetição sistemática de algumas rimas de música ou ao se deparar com um movimento repetitivo. Ele ficava o tempo inteiro fixado em alguns objetos, alheio aos outros, e quando alguém o pegava no colo, desencadeava-se uma crise de choro.

Quando Dale já tinha quase seis anos de idade, não demonstrava interesse por amigos ou pela família, mas no primeiro encontro com Henry, enquanto está assistindo a um 


\section{INTERACÃO EM LF PSICOLOGIA}

vídeo, sem olhar para o cachorrinho, começa a acariciá-lo. Logo no primeiro dia em casa, Dale lhe dá seu cobertor com a ilustração de máquina a vapor e exclama uma frase para se comunicar com seu amigo: "Hora de ir para a cama, Henry" (Gardner, 2008, p.45). Nessa noite, pela primeira vez na vida, Dale canta uma música parecendo brincar verbalmente.

Constatando que a presença de Henry era um alicerce de segurança para Dale, tranquilizando-o, o cachorro foi autorizado a circular à vontade pela casa. Seus pais começaram a se alicerçar em Henry para ensiná-lo os nomes das partes do corpo próprio, nomeando as partes do corpo de Henry; podiam observá-lo, a seguir, dizendo para o cachorrinho: "Esse é o seu nariz... sua pata. Estas são as suas orelhas... seus olhos" (Gardner, 2008, p. 47).

Antes da chegada do cachorro, Dale nunca tinha fome e sempre estabeleceu vários rituais para comer, como alimentos que não podiam tocar uns nos outros. Seus pais decidem utilizar o intermédio de Henry para nomear o estado de fome. Inicialmente, toda vez que viam o cachorro pedindo comida, perguntavam para Henry o que ele queria e respondiam que ele queria comer. Mas com o tempo, o próprio Dale designava quando o cachorro estava com fome, e que era a hora de ele comer. Dale aprende a organização das rotinas dos horários de refeição do cachorro e a preparação da comida também se torna um momento de aprendizagem por meio do qual assimila a sequência de ações necessárias para preparar a comida.

As alterações de rotina se tornam cada vez menos aterrorizadoras na presença de Henry. Dale tinha inúmeros rituais, como somente tomar banho à noite de acordo com uma organização específica do ambiente, mas junto com Henry consegue abrir mão desta necessidade de imutabilidade. Quando volta para casa imundo de lama após brincar com Henry, ao vê-lo entrando na banheira a plena luz do dia, espontaneamente pula na água e ambos tomam juntos um banho. Escovar os cabelos também é viabilizado pelo recurso a Henry. Nessa perspectiva, Nuala escovava o cachorro, falando que ele achava bom, que retirava os nós dos pelos, e em seguida, o próprio Dale o penteava e Nuala realça como Henry sentia prazer ao ser escovado. Então, Dale começou a conversar com Henry enquanto o escovava e progressivamente seu medo de ter os cabelos escovados se reduziu drasticamente.

Quando Dale realizava estereotipias, Henry entrava no meio do automatismo para pedir um carinho ou para brincar, e ao invés de desencadear uma crise, ele não se sentia invadido ou se enervava; ao contrário, sempre parava para interagir com Henry. Às vezes ele introduzia Henry no automatismo que realizava, por exemplo, mostrando para ele o trem com o qual realizava um movimento repetitivo, ou dava alguns de seus trens ao parceiro.
Enquanto Dale evitava olhar as pessoas, com Henry ele podia estabelecer o contato olho no olho por longos períodos de tempo, não somente não evitando esse contato, como demonstrando prazer e abertura para a intimidade, o que posteriormente pôde ser expandido para seu vínculo com os humanos.

Aos seis anos de idade, quando é avaliada a viabilidade de inserção em uma escola regular, solicita-se que desenhe algo para avaliar sua capacidade imaginativa e o controle do lápis. Dale desenha a imagem de Henry todo alegre com seus potes de comida e água, e escreve o nome do amigo. É a primeira vez na vida que Dale desenha um corpo, mas a partir de então, torna-se capaz de desenhar vários corpos, inclusive de humanos. Nessa época, seus desenhos prediletos - de locomotivas - ganham a atribuição de feições faciais e os trens começam a se entreolhar, sendo capazes de estabelecer o olho-no-olho.

É por meio do intermédio de Henry que Nuala consegue ensinar o controle das fezes e esfíncteres para Dale. Ele não somente não havia obtido esse controle, como manifestava pavor do vaso sanitário. Após inúmeras vezes escutar a mãe falar para Henry que não queriam deixar a casa toda suja e fedida, e que ele devia fazer os excrementos no lugar certo, ensinando-o a ir até o jardim, Dale começa a falar espontaneamente que precisava fazer xixi ou cocô, repetindo que não queria deixar a casa toda fedida e suja. Depois disso, nunca mais precisou usar fraldas. Durante alguns meses, ele continuava com medo da privada, então Nuala colocou pôsteres de seus trens prediletos no banheiro e junto com seus trens e Henry, ele pôde se sentir seguro e superar o medo.

Seus pais aproveitavam os momentos nos quais Dale estava falando com Henry para introduzir gentilmente novas palavras de modo a ampliar seu repertório de vocabulários e percebiam que ele não se sentia invadido, ao contrário da sua recusa de algumas palavras que outrora desencadeavam crises intensas.

Nuala e Jamie começam a personificar a voz do cachorro para falar com o filho, constatando que por esse intermédio ele podia "encontrar sua voz" (Gardner, 2008, 2013, p. 72), demonstrando-se mais suscetível a aceitar qualquer demanda intermediada por Henry. Progressivamente, os pais diminuíram a ênfase que aplicavam à voz personificando Henry e no decorrer de uma conversa, retomavam o próprio tom humano de voz. A partir do vínculo com Henry, Dale se abriu progressivamente para o mundo e para os outros, ancorado em uma mudança na sua relação com a linguagem e com o pensamento, alterando sua relação com o corpo próprio e, progressivamente, pôde tolerar tanto a voz quanto o olhar de seus pais. 


\section{WZINTERACÃO EM ¿T. PSICOLOGIA}

\section{DISCUSSÃO}

0 vínculo de Iris, Dale, George e Fraser com seus animais não são relacionamentos destrutivos ou deletérios. Muito pelo contrário. A relação com o parceiro/duplo animal é para eles paradigmático da abertura ao outro humano, sendo que o sentimento de segurança propiciado nesses relacionamentos favoreceu e potencializou a possibilidade de extensão da interação com os outros e o interesse pelo mundo.

No transcorrer das autobiografias acerca de Iris, Fraser Dale e George, surgiu de modo cada vez mais evidente um prazer no entrelaço com seus animais, que pôde se manifestar nas interações corporais, na vida imaginativa, no contar histórias, no compartilhamento da vida, na ancoragem das funções corporais, na aprendizagem e nas diversas modalidades de estar com os outros e poder se relacionar com os outros no mundo compartilhado.

A constituição e unificação do "eu" se dá progressivamente nos relatos a partir da integração dos traços dos duplos, mas podemos tecer a hipótese de que nessa modalidade de espelhamento, surge uma unificação da imagem total, unificante das partes do corpo próprio, sem que haja o olhar do outro parental enquanto aquele que se inscreve no seu circuito de prazer. Aqui surge uma Gestalt da imagem de si, do corpo próprio, pelo espelho/outro/animal, e há o surgimento de uma circulação da libido a partir da inscrição do traço do outro, em um registro de prazer, havendo uma mobilização do investimento libidinal que agora pode ser direcionado ao corpo próprio enquanto englobado nessa unidade ilusória. A incorporação desses traços dos outros, edificando lentamente a constituição de uma unidade equivalente a um "eu emergente" (Campos, 2009, p. 52), é correlata ao aparecimento de uma libido narcísica e a descrição de uma visualização e captura via essa imagem unificada composta por todos esses traços, viabilizando que esse "eu" seja tomado como objeto de investimento.

Podemos apontar nos casos analisados a importância da permeabilidade ao outro e a importância dessa primeira inscrição do prazer do outro para que haja a inscrição de Eros no circuito libidinal. Pesquisadores como a psicanalista Laznik (2010) tem demonstrado, por meio da análise de vídeos familiares de bebês, a importância de se detectar traços de prazer e de surpresa na voz no manhês, realçando a importância da inscrição desse prazer na relação com o outro. Nesse contexto, ao retomar a experiência de satisfação, seria retomado tanto o prazer obtido quanto o traço desse outro, na base da experiência de alucinação primária. Isso permite, segundo Laznik (2004), a emergência de um autoerotismo marcado pelos traços mnêmicos desse outro assegurador real, de modo que quando o bebê estivesse, por exemplo, chupando o dedinho, o prazer suscitado que já fora registrado traria o tra- ço da presença do outro.

É a partir da inscrição gentil de Billy, Thula, Ben e Henry no mundo autístico, por meio de uma presença delicada, não invasiva, repetindo e imitando os movimentos, que cada um destes parceiros/animais pôde estabelecer relações de prazer, lúdicas, a partir das quais levavam seus companheiros para o mundo compartilhado. Vale apontarmos que houve experiências de relacionamento destes autistas com outros animais que não se tornaram alicerces identificatórios, o que nos permite apontar a ressalva de que não se trata de uma indicação terapêutica de que todo animal seja terapêutico no autismo, mas sinalizar algumas características que tornaram estas relações singulares alicerces identificatórios. Nesse âmbito, podemos também realçar que os pais que descrevemos não seguiram cartilhas que determinavam que deveriam utilizar os animais como parte de uma terapia, mas se deixaram conduzir pelos vários indícios de que seus filhos ficavam menos angustiados na companhia desses amigos animais, o que se desdobrou, no decorrer do tempo, em evidências mais nítidas dos efeitos benéficos.

A modalidade de inscrição desses animais no mundo autístico, que se torna um mundo compartilhado, próximo do que Maleval (2009) sugere ser um autismo (compartilhado) a dois, se dá pela presença calma ao seu lado, pela entrada delicada no circuito autístico, através da imitação do animal dos movimentos do autista, pela sua inscrição nos automatismos ou no circuito de objeto, em um posicionamento discreto, não demandante, colocando-se de uma maneira não intrusiva, que permite ao autista inscrever esse animal singular, no seu tempo, e sob seu controle convidá-lo a interagir.

Ao ser inscrito no lugar de duplo autístico, cujo contato com o autista favorece a dinamização e a apropriação do corpo próprio, estabelece-se uma zona de prazer compartiIhado que pode se expandir progressivamente até ser partiIhado com pessoas. É pelo intermédio destes animais, que Dale, Iris, Fraser e George podem investir os outros, os objetos, o mundo de um modo geral, assim como é por esse intermédio que eles podem incorporar características e traços dos outros.

Essa edificação identificatória compensatória alicerçada na relação com esses animais tem efeitos como os que descreveremos, viabilizados pela apreensão global de si por meio de uma alienação à imagem do outro não humano, ancorando um anteparo imaginário para o espelhamento e apreensão de si. Este viés lhes permite criar pontos de contato libidinal entre o próprio corpo e a imagem do corpo do outro, oferecendo modalidades compensatórias ao funcionamento psíquico no autismo.

$\mathrm{Na}$ relação com seus parceiros animais, os autistas analisados puderam estabelecer diálogos que tinham uma dimen- 


\section{WIINTERACÃO EM ET PSICOLOGIA}

são apontada por Maleval (2015) como monólogos que os ajudavam a se expressar, podendo desde acalmar seus medos e ansiedades até aprender as regras da diplomacia social. É o recurso a esses parceiros não humanos que permitiu a George e Dale serem educados, aprendendo palavras, apreendendo as partes do corpo próprio, obtendo o controle corporal dos excrementos, aprendendo a organizar o tempo-espaço, acedendo à imagem do corpo próprio, se interessando pelo mundo e estabelecendo diálogos com os outros. Ao invés de evitar a qualquer custo olhar e ser olhado, com seus parceiros todos os autistas analisados aceitam o entreolhar ternamente de seus animais; ao invés de ter uma inibição para dialogar ou falar frases mais marcadas emocionalmente, nesses vínculos eles podem falar longamente e interagir a respeito de diversos assuntos.

Na história de George, é evidente o efeito de desvitalização ocasionado pela perda de seu duplo Ben, o que pode ser elucidado pela afirmação do psicanalista Maleval (2014) de que a perda do investimento dessa imagem do duplo (no caso animal) no qual o autista investia a libido, pode desencadear hemorragias libidinais. O psicanalista (Maleval, 2009, 2014) aponta que muitas vezes o autista precisa utilizar o recurso de uma imagem do duplo para poder se estruturar, realçando que uma das mais importantes saídas do autista do estado autístico é aquela que pela qual o autista pode localizar a libido não nas bordas do corpo próprio, mas nas bordas estabelecidas no ponto onde seu corpo e o corpo/imagem do corpo de seu duplo se conectam.

A partir da análise dos relatos autobiográficos, demonstramos a importância para esses autistas desses duplos autísticos enquanto bordas que viabilizam uma regulação libidinal do autista e a apropriação do corpo próprio. Podemos apontar algumas distinções entre as formulações dos psicanalistas Maleval (2017) e Laznik $(2004,2016)$ acerca da constituição das bordas e os circuitos libidinais, de modo a elucidarmos algumas nuanças da dinamização psíquica que observamos nos casos estudados e que remetemos a uma identificação compensatória. Na clínica do autismo, a psicanalista Laznik (2004) problematiza a constituição da imagem de si e do outro, formulando que o circuito pulsional não pode se instaurar de modo a que a libido se concentre nas zonas erógenas. Nesse âmbito, ela afirma que essas zonas não fazem borda ${ }^{2}$ no autismo. Ancorada nessas teorizações, alicerçada principalmente na sua vasta experiência clínica com crianças autistas e com bebês, a psicanalista afirma que "as crianças autistas têm uma falha no campo do Imaginário" (Laznik, 2016, p. 44), referindo-se principalmente à conceituação lacaniana do Estádio do Espelho, abarcando a construção do eu enquanto uma instância imaginária remetida a uma alienação ao outro humano. Com base neste repertório teórico-clínico sua ênfase se deslocou para a intervenção precoce com destaque para a importância da prosódia e da inscrição do registro do prazer no circuito pulsional, que inclua um traço do outro humano.

Já o psicanalista Maleval (2017) parte desse mesmo campo psicopatológico, mas sua ênfase não será em modalidades de intervenção precoce e, ao contrário de Laznik que enfocará a saída do quadro do autismo em bebês e crianças pequenas, Maleval enfocará uma evolução dentro das manifestações do próprio quadro de autismo, sendo que dada a temática do presente artigo nos limitaremos a aprofundar algumas especificidades de como ele abarca a identificação compensatória, remetida a uma alienação imaginária. 0 psicanalista formula haver no autismo uma retenção dos objetos (pulsionais) implicados nas relações com os outros humanos, de modo que o autista evita ceder esses objetos, retendo o objeto oral, o objeto anal, bem como a voz e o olhar. No entanto, a hipótese original do psicanalista é que ao invés da libido ficar transbordante sem poder se fixar em nenhum lugar, seria possível a criação de compensações no âmbito imaginário, que o psicanalista articula ao investimento de bordas autísticas, sendo que enfocamos no presente texto a origem das bordas ancoradas nos duplos autísticos animais, por meio de uma alienação imaginária compensatória. Notamos nas autobiografias analisadas que houve um tratamento (imaginário) dos objetos pulsionais oral, anal, voz e olhar, por meio do intermédio dos animais/duplos, de modo que foi viabilizada uma nova regulação, uma cessão parcial destes, que puderam entrar na relação com o outro, que puderam ser perdidos sob controle do autista, nesse vínculo de confiança, por meio de uma cessão operacionalizada pelas bordas constituídas no ponto de contato do próprio corpo com (a imagem) do corpo do duplo/animal.

Podemos retomar algumas das formulações de Maleval (2017) acerca destas bordas para elucidar seu papel em uma (possível) nova economia libidinal no autismo. A psicanalista Soler (1999) afirmava que o corpo libidinal do autista estava em pane. Ao contrário desse caos, por impossibilidade de localização da libido nas zonas erógenas, remetido ao que Laznik (2004) formula enquanto a não circulação e não fixação da libido nas bordas do corpo; o viés do duplo permite, segundo Maleval (2017), que o autista delimite "o ponto de inserção da sua libido, ali onde ela se encontra localizada, isto é, na sua borda, e não lá onde ela é caótica - no seu corpo" (p. 128). Vale sublinharmos a distinção de Maleval entre a inserção da libido no corpo, nas zonas erógenas do corpo, e a inserção da libido nas bordas, muitas vezes na borda da imagem do duplo.

Dessa maneira, para Maleval, há uma canalização da libido, uma forma de acessar essa libido, por meio destas bordas auto-inventadas no autismo. Ao se apropriar dos traços 


\section{W'INTERACÃO EM ET PSICOLOGIA}

dos outros, "uma das funções do duplo era dar consistência a um eu ideal factício" (p. 131), fornecer "um suporte para uma enunciação artificial" (p. 131) e viabilizar uma regulação da economia libidinal, alicerçada na localização da libido nessas bordas. No início do texto, delimitamos nossa ênfase no presente trabalho na edificação egóica, intermediada pelo espeIhamento em um outro não humano, e sua relação com uma nova circulação libidinal e a constituição do narcisismo. Enfocamos, portanto, a constituição compensatória do eu, oriundo de um espelhamento compensatório, o que é distinto da formulação da vertente laznikiana de formulação desta falha no autismo em termos da "impossibilidade da instauração do tempo constitutivo do imaginário, e então do eu, através da relação especular com o Outro" (Laznik, 2004, p. 53). Ao contrário da formulação do autismo como uma "clínica de uma não instauração da relação especular" (p. 50), da falha do estádio do espelho, abarcamos por meio das formulações de Maleval a viabilidade de construções compensatórias que permitem a constituição de um estofo imaginário no autismo, edificando uma apropriação dos traços do outro e uma apreensão de si por meio da imagem de um outro - no caso desse texto, por meio da imagem de animais. Nesse âmbito, formulamos que investindo a libido nessas bordas, ancorando-se nesse outro/duplo/animal, é constituído e solidificado o espaço imaginário, e instaurada a imagem do corpo próprio, alicerçando uma alienação (imaginária) compensatória. Não se trata de uma identificação simbólica, mas de uma identificação imaginária que ancora a constituição do eu e do eu ideal, tendo sido instaurada a operação de alienação imaginária ao duplo animal.

Ao contrário de um imaginário alicerçado na imagem do outro humano, esta vertente de formulação se alinha com uma concepção de um "espelho [que] não está dado a priori" (Pacheco, 2014, p. 39). Isto é, se por um lado enfocamos a importância psíquica desse investimento da imagem do outro para a constituição da imagem de si e do corpo próprio, por outro enfatizamos como essa edificação imaginária pode se dar por percursos inusitados, o que será enfatizado em posteriores construções teóricas no campo lacaniano, como a que acabamos de citar da psicanalista Pacheco, e que procuram abarcar o imaginário lacaniano a partir da topologia, o que não foi o foco do presente texto. A análise dos relatos autobiográficos nos permitiu observar o surgimento da imagem de si, espelhada em um duplo/animal e, nessa linha de argumentação, no caso de Dale, Fraser, Iris e George formulamos a invenção de espelhos e a edificação de identificações (não materna, não paterna, e podemos mesmo dizer não feminina e não masculina) na origem da incorporação dessas alteridades e da identificação constitutiva do eu no autismo.

\section{CONSIDERAÇÕES FINAIS}

A maneira pela qual cada autista encontra para sair do quadro de retraimento autístico e abertura para o laço social é privilegiadamente original. Nesse âmbito, as autobiografias analisadas evidenciam a importância da potencialização de um vínculo original como o estabelecido com Thula, Ben, Billy e Henry. No autismo, trata-se de uma maneira singular de poder se relacionar com os outros e de poder estar no mundo, retratando um modo de funcionamento psíquico distinto que exige uma abordagem terapêutica e educativa particular e não padronizada de cada autista. Nesse âmbito, em contraposição a uma abordagem normativa, podemos concluir realçando a importância dos pais de Iris, Fraser, George e Dale se deixarem conduzir pela constatação do alívio da angústia nessa relação e da importância subjetiva deste vínculo, corroborando a afirmativa da psicanalista Perrin (2009) de que "a solução que o sujeito autista encontra é sempre original, única" (p. 96), e nesse sentido, o trabalho psicanalítico deve se balizar nessa invenção do autista, na sua paixão particular, o que sinaliza uma posição ética, clínica e política de respeito à singularidade.

\section{DECLARAÇÃO DE CONFLITOS DE INTERESSE}

A autora declara que não há conflitos de interesse no manuscrito submetido

\section{AGRADECIMENTOS}

A autora agradece ao Grupo de Pesquisa coordenado pelo Prof. Nelson Coelho Júnior - PSE/USP.

\section{REFERÊNCIAS}

Booth, L. (2014). When Fraser met Billy: The rescue cat that transformed a little boy's life. London: Hodgger \& Stoughton.

Campos, E. B. V. (2009). Representação e afeto no segundo modelo tópico e pulsional freudiano. (Tese de Doutorado, Instituto de Psicologia da Universidade de São Paulo). http://dx.doi.org/10.11606/T.47.2009.tde-04122009140125

Campos, E. B. B. \& Coelho Jr., N. E. (2010). Incidências da hermenêutica para a metodologia da pesquisa teórica em psicanálise. Estudos de psicologia (Campinas), 27 (2), 247-257.

http://dx.doi.org/10.1590/S0103-166X2010000200012 


\section{-4: INTERACÃO EM IF PSICOLOGIA}

Carter-Johnson, A. (2016). Iris Grace: The story of a little girl whose talent unlocked her silent world. Wemding, GER: Penguin/Michael Joseph.

Gardner, N. (2008). A friend like Henry: The remarkable true story of an autistic boy and the dog that unlocked his world. Naperville, IL: Sourcebooks.

Gardner, N. (2013). All because of Henry: My story of struggle and triumph with two Autistic children and the dogs that unlocked their world. Naperville, IL: Sourcebooks.

Kupfer, M. C. K. (2004). Autismo: Uma estrutura decidida? Uma contribuição dos estudos sobre bebês para a clínica do autismo. Em Coloquio do LEPSI IP/FE-USP, 5., 2004, São Paulo.

Laznik, M-C (2004). A voz da sereia: 0 autismo e os impasses na constituição do sujeito. Salvador, BA: Agalma.

Laznik, M-C. (2010). Godente ma non troppo: O mínimo de gozo do outro necessário para a constituição do sujeito. Revista Psicologia Argumento, 28 (61), 135-45.

Laznik, M-C. (2016). Podemos pensar uma clínica do nó borromeo que distingue a psicose e o autismo nos bebês? Em M-C. Laznik.; B. Touati \& C. Bursztejn (Org). Distinção clínica e teórica entre autismo e psicose na infância (pp. 27- 55). São Paulo: Instituto Langage.

Maleval, J-C. (2009). L'autiste et sa voix. Paris: Éditions du Seuil.

Maleval, J-C. (2014) Re:Un animal comme bord autistique. (Blog post). Recuperado de: <http://www.autistes-et-cliniciens.org/Un-animal-comme-bord-autistique.
Maleval, J-C. (2015). Affinity therapy: The return of a psychodynamic approach to the treatment of autism. (Blog post). Recuperado de http://www.autistes-et-cliniciens.org/Affinity-Therapy-The-Return-of-a-PsychodynamicApproach-to-the-Treatment-of

Maleval, J-C. (2017). O autista e a sua voz (Trad. P. S. de Souza Jr). São Paulo: Editora Blucher.

Pacheco, A. L. P. (2014). Na mansão do dito imaginário: Opsis e a seção diagonal. Stylus (Rio de Janeiro), 29, 33-42.

Perrin, M. (2009). Construction d'une dynamique autistique de l'autogire à la machine à laver. Em J-C. Maleval (Org.). L'Autiste, son double et son objet (pp. 69-100). Rennes: Presses Universitaires de Rennes.

Romp, J. (2010). The cat who came for Christmas: How a cat brought a family the gift of love. New York: A plume book/Penguin Group.

Soler, C. (1999). Autismo e paranoia. Em S. Alberti. (Org.) Autismo e Esquizofrenia na clínica da esquize. (pp. 219-232). Rio de Janeiro, RJ: Marca d’Água.

Recebido em: 13/02/2017

Primeira decisão editorial em: 21/07/2017

Aceito em: 19/09/2017

\footnotetext{
1 "Ever since we came home with Thula, this precious magical kitten has cast a spell over Iris; They sit beside each other as Iris paints, and new doorways to communication have opened, doors we have previously feared might be locked for ever" (Carter-Johnson, 2016, contracapa).

2 "Isso assume toda importância clínica quando nos lembramos a que ponto, nas crianças autistas, essas zonas não fazem borda - seus lábios deixam escorrer a saliva, os esfíncteres não funcionam como tal. Isso por não terem sido zonas de investimento erógeno, por não terem sido tomadas num circuito pulsional". (Laznik, 2004, p. 60).
} 